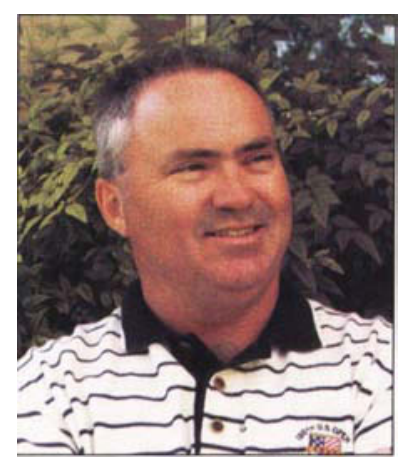

Costs uncertain:

\section{Methyl bromide phase-out becomes reality}

\author{
COLIN CARTER \\ Chair, Department of Agricultural \\ and Resource Economics \\ UC Davis
}

$\mathrm{O}$ ne of the vexing problems confronting California farmers today is the unknown cost of compliance with new state and federal regulations on methyl bromide use.

Methyl bromide has been regulated under the U.N.

Montreal Protocol as an ozone-depleting substance since 1992. The protocol calls for a $50 \%$ reduction in the quantity of methyl bromide sold in the United States this year, using 1991 as a baseline. By 2005, the protocol bans most uses.

The state of California has also regulated methyl bromide since 1994, in response to concerns about toxicity to farm workers and nearby residents. Until recently, state regulations took the form of discretionary controls set by each county. Now the California Department of Pesticide Regulation (CDPR) is codifying county-level guidelines to make them state law, and adding more stringent restrictions. These changes may have the effect of phasing out methyl bromide use in some areas even before the global phase-out.

The loss of methyl bromide is a real threat to strawberry production and other commodities as well. Until this year California growers typically applied about 16 million pounds of methyl bromide to the soil annually, one-half of the national total. Strawberry growers, by far the largest users in California, accounted for about one-third of the statewide use. The chemical is also important in the production of nursery and ornamental plants, fruits and vegetables, and tree and vine crops.

One UC analysis projects that total strawberry industry revenues will fall by about $15 \%$ under the 2005 methyl bromide ban, due to the nature of consumer demand for this fruit. The price of strawberries will rise, but the increase will be insufficient to offset the lower yields and higher preharvest costs.

Methyl bromide is a natural substance, and therefore a large share of total methyl bromide emissions occurs through oceanic, plant and soil discharge. Agricultural use of the synthetic chemical is but one of several sources of atmospheric methyl bromide. Although their views are controversial, some scientists believe the ban on agricultural uses will have a small effect on the ozone.

The terms of the Montreal Protocol could lead to increased competition from farmers abroad. While U.S. growers must phase out methyl bromide for most uses by 2005, farmers in developing countries, such as China and Mexico, have an extra 10 years to do so.

Meanwhile, the fumigant's price in the United States has escalated. To date there is no single replacement chemical as effective for controlling diseases and weeds (see p. 10). The best substitute chemical has limits on use within townships (see p. 12), and the latest state regulations will be very costly to farmers.
The higher price of methyl bromide has already made some agricultural uses in California uneconomical. The U.S. Environmental Protection Agency (EPA) decided to implement methyl bromide's phase-out by simply regulating the amount manufactured (and imported), allowing market prices to allocate the available supply. Only two domestic firms and one foreign firm manufacture methyl bromide. As a result of a lack of competition at the manufacturing level and EPA limits on the amount sold, prices have more than doubled for California growers in the last few years.

Adding pressure to an already difficult situation, CDPR recently imposed its own set of methyl bromide application restrictions, effective January 2001, partly in response to a 1998 lawsuit initiated by environmental groups.

These state-level regulations were introduced to reduce human exposure to methyl bromide. For each fumigation site, the regulations stipulate dual buffer zones that depend on such factors as application rate, method of application and proximity of the field to public roads, houses or other occupied buildings. In addition, the regulations contain extensive worker hour restrictions. Additional worker and machinery time may be required as it could take three to four times longer to fumigate each field. Some growers will have no choice but to change their method of fumigation. In Santa Barbara County, for instance, growers will be faced with such large buffer zones that they will have to switch fumigation methods, and their fumigation costs will double as a result.

The CDPR regulations will also impose a relatively higher cost on growers with smaller fields, especially those on the urban fringe (for example, Orange County). A strawberry grower with a 20-acre field next to a public road could lose more than $10 \%$ of his acreage due to buffer-zone requirements, whereas his neighbor down the road with an 80-acre block would only lose about $3 \%$ of his acreage.

Growers will have to re-evaluate, rethink and reconfigure their cropping systems. In addition to field and laboratory research into alternatives, UC researchers are also investigating the economic decision-making process. Developing a comprehensive approach to measuring the farm- and industry-level economic effects is not only important for the methyl bromide issue, but also for the next chemical in line for more stringent environmental regulations. Economists can help develop more sensible ways of regulating chemical usage in agriculture, accounting for both farm and environmental interests and impacts. 